Cahiers $d u$ MONDE RUSSE

\section{Cahiers du monde russe}

Russie - Empire russe - Union soviétique et États indépendants

$46 / 4 \mid 2005$

L'invention d'une politique humanitaire

\title{
Mark J. Sedgwick, Against the Modern World
}

Marlène Laruelle

\section{OpenEdition \\ Journals}

Édition électronique

URL : https://journals.openedition.org/monderusse/6662

DOI : 10.4000/monderusse. 6662

ISSN : $1777-5388$

Éditeur

Éditions de l'EHESS

Édition imprimée

Date de publication : 1 décembre 2005

Pagination : 971-973

ISBN : 2-7132-2057-2

ISSN : $1252-6576$

Référence électronique

Marlène Laruelle, "Mark J. Sedgwick, Against the Modern World », Cahiers du monde russe [En ligne], 46/4 | 2005, mis en ligne le 30 juin 2009, consulté le 04 septembre 2022. URL : http://

journals.openedition.org/monderusse/6662 ; DOI : https://doi.org/10.4000/monderusse.6662

Ce document a été généré automatiquement le 4 septembre 2022.

Tous droits réservés 


\title{
Mark J. Sedgwick, Against the Modern World
}

\author{
Marlène Laruelle
}

\section{RÉFÉRENCE}

Mark J. SEDGWICK, Against the Modern World. Traditionalism and the Secret

Intellectual History of the Twentieth Century. Oxford, New York : Oxford University

Press, 2004, $370 \mathrm{p}$.

1 Le traditionalisme est un courant de pensée qui a été, proportionnellement à d'autres doctrines religieuses et politiques, très peu étudié et ce, alors qu'il a inspiré de manière plus ou moins discrète de nombreux penseurs du $\mathrm{xx}^{\mathrm{e}}$ siècle : les fondateurs René Guénon et Julius Evola, mais aussi les auteurs du traditionalisme dit «mou» comme Mircea Eliade et Karl Jung, ceux du traditionalisme dit «dur », comme Titus Burckhardt, ceux convertis au soufisme, comme Frithjof Schuon, ou à l'islamisme, comme Claudio Mutti. Il constitue également un courant présent en Union soviétique et dans la Russie contemporaine, que Mark Sedgwick se propose de remettre en contexte au sein d'un ensemble idéologique plus large, celui de l'histoire de ce mouvement tout au long du $\mathrm{xx}^{\mathrm{e}}$ siècle.

2 Les deux premières parties du livre sont consacrées aux différentes étapes de constitution de la pensée guénonienne. Dans les années 1920, René Guénon (1886-1951) formalise les principaux concepts du traditionalisme dans cinq œuvres: Introduction générale à l'étude des doctrines hindoues (1921), Le théosophisme, histoire d'une pseudo-religion (1921), L'erreur spirite (1923), Orient et Occident (1924), La crise du monde moderne (1927). Après une phase catholique puis spirite (dans une loge théosophique puis dans l'ordre martiniste), durant laquelle il découvre les religions orientales et éprouve une déception par rapport à un Occident qu'il pense incapable de reconstituer un lien mystique avec la foi, il quitte la France pour Le Caire, où il rallie un ordre égyptien et tente de mettre en pratique ses préceptes traditionalistes dans le soufisme. Durant ces années 1930, sa pensée 
se répand en Italie, en Allemagne et en Roumanie : elle devient l'un des mots d'ordre des courants spirites fascistes, et il faut mentionner à ce titre l'œuvre du principal disciple de Guénon, Julius Evola (1896-1974), peintre italien proche des dadaïstes dont l'un des livres, Révolte contre le monde moderne (1934), eut une grande influence sur les mouvances néo-païennes allemandes et italiennes.

Le traditionalisme croit en la Tradition, c'est-à-dire en l'existence d'un monde stable dans ses principes religieux, philosophiques et sociaux qui aurait commencé à disparaître dès le $\mathrm{XVI}^{\mathrm{e}}$ siècle avec la modernité. Celle-ci est considérée comme néfaste en ce qu'elle détruit l'ordre préétabli alors que celui-ci représenterait la naturalité du monde, la hiérarchisation des hommes étant transcendante et ayant une valeur mystique. La Tradition aurait été mieux préservée dans d'autres civilisations qu'en Occident, mais l'action de remise en cause du passé inaugurée par celui-ci dès la Renaissance se serait propagée, avec les expériences coloniales, dans les autres espaces culturels. Cette analyse, typique - sur le plan des théories politiques - de la pensée contre-révolutionnaire (de Maistre, Bonald), trouve chez Guénon un accent religieux qui fait la spécificité du traditionalisme au sein du courant d'idées dit conservateur. Pour Guénon en effet, toutes les religions et traditions ésotériques, quelle que soit la forme concrète de leur pratique, révèlent l'existence, aujourd'hui disparue, d'une Tradition sacrale originelle, qu'il nomme "Tradition primordiale» et qui serait l'essence secrète de toutes les religions. Il invite alors le monde moderne à reprendre conscience de cette unité face à la désacralisation et à la sécularisation contemporaines, et à ce titre il a influencé de très nombreux courants gnostiques, maçonniques, ainsi que plusieurs ordres soufis.

Le traditionalisme connaît une nouvelle impulsion dans les années 1950-1960, ce qu'étudie la troisième partie du livre. Son principal impact intellectuel se remarque au sein du monde musulman, dans plusieurs ordres soufis auxquels a été lié René Guénon, puis l'un de ses disciples, Frithjof Schuon. Celui-ci participe à la fondation du principal ordre soufi traditionaliste, Alawiyya, renommé par la suite Maryamiyya. Les dissensions doctrinales ont été nombreuses au sein du traditionalisme musulman, mais la pensée guénonienne a connu d'importants succès après la Seconde Guerre mondiale aussi bien dans l'Iran des shahs qu'au Maroc et en Turquie. La quatrième et dernière partie de l'ouvrage, intitulée "Le traditionalisme et le futur», est dédiée aux courants traditionalistes qui se sont développés en Europe occidentale après 1968 ainsi que dans les cercles intellectuels de l'islam radical, en particulier avec la révolution islamique iranienne. Un chapitre y est spécifiquement consacré à la Russie.

Certains écrits traditionalistes semblent connus en URSS dès les années 1960 grâce au poète Evgenij Golovin et à sa découverte du Matin des magiciens de Louis Pauwels. Dans la deuxième moitié des années 1970, émerge à Moscou un cercle dissident occultiste inspiré par le traditionalisme, qui regroupe, parmi ses principales figures, son fondateur Evgenij Golovin, le philosophe chrétien Jurij Mamleev (membre d'un officieux Ordre noir SS (Černyj orden) en URSS, et qui quittera le pays pour les États-Unis), le jeune Aleksandr Dugin ainsi que le penseur musulman Gejdar Džemal. L'unité idéologique de ce groupe se fait dans le rejet aussi bien de l'expérience soviétique et du modèle occidental que du slavophilisme. Ces mêmes personnalités, qui ont par la suite suivi des parcours intellectuels et politiques différents, se retrouvent aujourd'hui encore au sein d'une petite structure nommée l'Université nouvelle (Novyj Universitet), créée en 1998 et qui diffuse, à des cercles restreints mais influents, la pensée traditionaliste. 
6 C'est bien entendu la personnalité et l'œuvre de Dugin qui occupe la majeure partie de ce chapitre, ainsi que celles de Gejdar Džemal, intellectuel d'origine azérie, fondateur du parti de la Renaissance islamique d'URSS et qui s'est aujourd'hui rapproché de l'islamisme. Initié au traditionalisme très jeune, Dugin, dès 1981, traduit en russe et diffuse en samizdat L'impérialisme païen de Julius Evola. Cette activité clandestine ainsi que la possession de livres interdits lui vaudront d'être expulsé de l'Institut d'aviation de Moscou où il étudiait. Au sein des divers courants traditionalistes, Dugin ne se contente pas de la recherche d'une voie spirituelle intérieure individuelle, comme celle par exemple de A.K. Coosmaraswamy (1877-1947), concentrée sur l'aspect esthétique du traditionalisme. Il est bien plus proche de la pensée d'Evola, qui avait développé une vision politisée du courant, et n'hésite pas à affirmer sa conception sacrificielle du politique. Sedgwick invite alors à une plus juste prise en compte des soubassements traditionalistes présents au sein des doctrines néo-eurasistes propagées par Dugin, qu'illustre son parcours politique complexe allant du parti national-bolchevik à la fondation du mouvement Evrazija et à son ralliement à Vladimir Putin.

7 Bien que ce chapitre soit court et que l'auteur n'ait pu se consacrer à une étude exhaustive du traditionalisme chez Dugin et Džemal, on ne peut qu'apprécier sa pertinence et se féliciter du regard d'un non-spécialiste du monde russe sur ces figures contemporaines. Le livre de Mark Sedgwick offre en effet une analyse approfondie de ce courant intellectuel si peu connu. Ce regard original nourri d'une connaissance étendue de l'islam et du monde musulman ne peut qu'être bénéfique à une prise de conscience de l'impact du traditionalisme hors des pays occidentaux. La Russie trouve ainsi sa juste place dans une histoire plus large, ce livre démontrant avec succès l'européanité de l'histoire intellectuelle russe et la nécessité de rattacher les courants doctrinaux russes contemporains à des mouvances plus générales présentes hors du monde russe et soviétique. 